\title{
Communication \\ Slow-Relaxation Behavior of a Mononuclear Co(II) Complex Featuring Long Axial Co-O Bond
}

\author{
Zhengyao Xia ${ }^{1}$, Yan $\mathrm{Li}^{2}$, Cheng $\mathrm{Ji}^{1}$, Yucheng Jiang ${ }^{1, *}$, Chunlan Ma ${ }^{1}$, Ju Gao ${ }^{1,3, *}$ and Jinlei Zhang ${ }^{1, *}$ \\ 1 Jiangsu Key Laboratory of Micro and Nano Heat Fluid Flow Technology and Energy Application, School of \\ Physical Science and Technology, Suzhou University of Science and Technology, Suzhou 215009, China; \\ zhengyaoxia@163.com (Z.X.); jcspst@126.com (C.J.); wlxmcl@mail.usts.edu.cn (C.M.) \\ 2 School of Environmental Science and Engineering, Suzhou University of Science and Technology, \\ Suzhou 215009, China; ly15822867871@163.com \\ 3 School of Optoelect Engn, Zaozhuang University, Zaozhuang 277160, China \\ * Correspondence: jyc@usts.edu.cn (Y.J.); jugao@hku.hk (J.G.); zhangjinlei@usts.edu.cn (J.Z.)
}

Citation: Xia, Z.; Li, Y.; Ji, C.; Jiang, Y.; Ma, C.; Gao, J.; Zhang, J. Slow-Relaxation Behavior of a Mononuclear Co(II) Complex Featuring Long Axial Co-O Bond. Nanomaterials 2022, 12, 707. https://doi.org/10.3390/ nano12040707

Academic Editor: Danil N. Dybtsev

Received: 21 January 2022

Accepted: 18 February 2022

Published: 21 February 2022

Publisher's Note: MDPI stays neutral with regard to jurisdictional claims in published maps and institutional affiliations.

Copyright: (c) 2022 by the authors. Licensee MDPI, Basel, Switzerland. This article is an open access article distributed under the terms and conditions of the Creative Commons Attribution (CC BY) license (https:// creativecommons.org/licenses/by/ $4.0 /)$.

\begin{abstract}
Co}(\mathrm{II})$ mononuclear complex with different coordination geometry would display various of field-induced single-ion magnet (SIM) behaviors. Here, we identify a field-induced single-ion magnet in a mononuclear complex $\mathrm{Co}\left(\mathrm{H}_{2} \mathrm{DPA}\right)_{2} \cdot \mathrm{H}_{2} \mathrm{O}\left(\mathrm{H}_{2} \mathrm{DPA}=2\right.$,6-pyridine-dicarboxylic acid $)$ by the hydrothermal method. The long axial Co-O coordination bond (Co1 ‥O3) can be formed by $\mathrm{Co} 1$ and O3. Therefore, $\mathrm{Co}(\mathrm{II})$ ion is six-coordinated in a distorted elongated octahedron. AC magnetization susceptibilities show that the effective energy barrier is up to $43.28 \mathrm{~K}$. This is much larger than most mononuclear $\mathrm{Co}(\mathrm{II})$. The distorted elongated octahedron caused by the axial Co-O coordination bond is responsible for the high effective energy barrier. The distribution of electron density in $\mathrm{Co} 1$ and $\mathrm{O} 3$ atoms in the long axial bond would influence the magnetic relaxation process in turn. Our work deepens the relationship between the effective energy barrier and the weak change of ligand field by long axial bonds, which would facilitate constructing SIM with high energy temperature.
\end{abstract}

Keywords: single-ion magnet; high effective energy barrier; long axial bond

\section{Introduction}

The first single-ion magnet (SIM) [Tb(III) $\mathrm{Pc}_{2}$ ] was reported in 2003 [1]. From then, a lot of lanthanide-based SIMs were prepared and studied owing to their large single-ion magnetic anisotropies which may lead to higher energy barriers [2-7]. Owing to the valence orbitals of transition metal ions, the $3 \mathrm{~d}$ orbital angular momentum could be quenched easier than that of lanthanide by the ligand field. Therefore, the magnetic anisotropy of a transition metal based complex could be greatly owned to the second-order spin-orbit coupling in the mixed states between excited and ground states [8,9]. Among the transition metal ions, $\mathrm{Co}$ (II) ion has been mostly researched owing to its strong magnetic anisotropy. In addition, $\mathrm{Co}(\mathrm{II})$ ion based complex show numerous coordination geometries such as two coordination [10], three coordination [11], four coordination [12,13], five coordination [14], six coordination [15-17], seven coordination [18] and eight coordination [19].

Until now, most reported field-induced SIM behavior is shown in the six-coordinated $\mathrm{Co}(\mathrm{II})$ mononuclear complex. As the central symmetry of paramagnetic complex plays an important role in the slow relaxation. Their magnetostructural relationships have been studied deeply [8]. Song's group has even reported the relationship between the coordination geometry of $\mathrm{Co}(\mathrm{II})$ ions and slow relaxation in the six-coordinated $\mathrm{Co}(\mathrm{II})$ complex in 2018 [20]. However, there are few studies on SIMs with a distorted elongated octahedron coordination environment of $\mathrm{Co}$ (II) ions in the complex. The effects of the weak change of the ligand field on the slow relaxation and the positive/negative value of $D$ are still insufficient in $\mathrm{Co}$ (II) complexes $[7,21-37]$. Therefore, it is necessary to study the relationship 
between magnetic characteristics and the long axial Co-O bond in Co(II) complexes with SIMs behavior. Here, we synthesized a six-coordination mononuclear cobalt complex $\mathrm{Co}\left(\mathrm{H}_{2} \mathrm{DPA}\right)_{2}\left(\mathrm{H}_{2} \mathrm{O}\right)\left(1, \mathrm{H}_{2} \mathrm{DPA}=2\right.$,6-pyridine-dicarboxylic acid $)$ with a distorted elongated octahedron environment, which shows field-induced slow-relaxations. We demonstrate that the distorted octahedron caused by the long axial $\mathrm{Co}-\mathrm{O}$ bond $(\mathrm{Co} 1 \cdots \mathrm{O} 3)$ could play an important role in increasing the effective energy barrier of SIM, which is about $43.28 \mathrm{~K}$.

\section{Materials and Methods}

First, $2.0 \mathrm{mmol}$ piperazine $(172.28 \mathrm{mg})$ in $10 \mathrm{~mL} \mathrm{C}_{2} \mathrm{H}_{5} \mathrm{OH}$ was added dropwise to $0.5 \mathrm{mmol} \mathrm{CoCl}_{2} \cdot 6 \mathrm{H}_{2} \mathrm{O}(118.97 \mathrm{mg})$ and $0.5 \mathrm{mmol} \mathrm{H} \mathrm{H}_{2} \mathrm{DPA}(83.56 \mathrm{mg})$ in $20 \mathrm{~mL} \mathrm{H}_{2} \mathrm{O}$. Then, by filtering and evaporating naturally at room temperature for three days [38-40], we obtained crystals with the distorted octahedral geometry named complex $\mathbf{1}$. The yield of the complex crystal is about $40 \%$.

Crystallographic data for the selected complex 1 crystal were obtained at $296 \mathrm{~K}$ through Bruker D8 Venture [41-43]. The structure data were uploaded in a CIF file. Detailed structural analysis is displayed in Table S1 in the Supplementary Materials. The related distances and angles are listed in Table S2. The experimental XRD pattern was collected by Bruker D8 Advanced, and the simulated XRD pattern was fitted by the software of Diamond. The magnetization was measured from 1.8 to $300 \mathrm{~K}$ by SQUID (MPMS-XL 7). Then, measurements of isothermal magnetization were carried out from 0 to $7 \mathrm{~T}$. The corresponding AC susceptibility of the same crystals was also measured at different external fields, with different frequencies from 1 to $999 \mathrm{~Hz}[44,45]$.

\section{Results and Discussion}

\subsection{Structure}

By the analysis of single crystal X-ray diffraction, this Co(II) based complex $\mathbf{1}$ is monoclinic with a space group of $\mathrm{P} 21 / \mathrm{n}$. Every $\mathrm{Co}$ (II) ion is six-coordinated in a distorted elongated octahedron (Table S3) with two $\mathrm{H}_{2}$ DPA molecules and one water (Figure 1a). All the square positions of the distorted elongated octahedron are occupied by O7, O12, N1 and $\mathrm{N} 2$ respectively, where two oxygen and two nitrogen atoms are from $\mathrm{H}_{2} \mathrm{DPA}$ ligands. The last oxygen atom named $\mathrm{O} 1$ is from water. Obviously, all the $\mathrm{Co}-\mathrm{O} / \mathrm{N}$ coordinated bonds are in the range for a high spin of $\mathrm{Co}$ (II) ion. Among them, the $\mathrm{Co}-\mathrm{O}$ bond lengths are $2.0539,2.0620$, and $2.1042 \AA$, respectively, and Co-N ones are 2.0719 and $2.1423 \AA$ for 1 , respectively. Note that the adjacent Co1 ‥ O3 distance is $2.4265 \AA$ named as the long axial bond, which is much longer than that in the similar mononuclear Co complex. There is a strong $\pi \cdots \pi$ stacking (3.4199 $\AA$ ) between the nearest molecules along the $\boldsymbol{a}$ axis as shown in Figure 1b. Then the nearest two molecules form a one-dimensional (1D) chain along $c$ axis by $\pi \cdots \pi$ stacking $(3.5731 \AA$ ), therefore constructing its three-dimensional structure of complex 1 (Figure 1c). The morphology of complex $\mathbf{1}$ crystals showing distorted octahedral geometry is displayed in the inset of Figure 1d. The crystal edge length of the geometry is about $0.5 \mathrm{~mm}$. Then XRD spectra can be acquired from the grinded powders of the selected complex crystals in Figure 1d (olive line). By contrasting the simulated spectra (orange line), we can confirm the structure analysis of complex $\mathbf{1}$. 


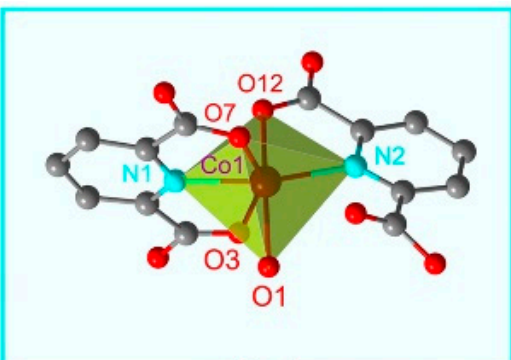

(a)

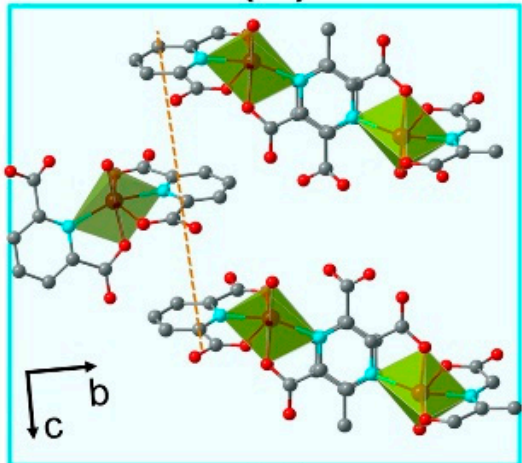

(c)

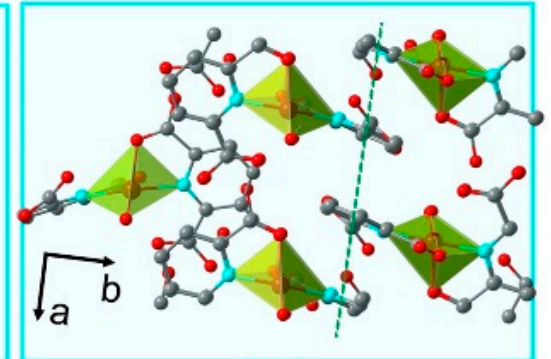

(b)

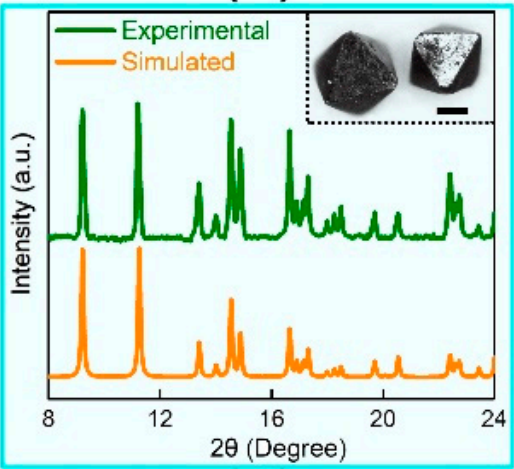

(d)

Figure 1. Atomic structure of 1. (a) The distorted elongated octahedron centered with a Co(II) ion; (b,c) two different $\pi \cdots \pi$ stackings along $\boldsymbol{a}$ axis (b) and $c$ axis (c) in $\mathbf{1}$ respectively; (d) XRD spectra of experimental and simulated $\mathbf{1}$. The inset is the morphology of crystal complex $\mathbf{1}$. The scale bar is $0.2 \mathrm{~mm}$.

\subsection{Magnetic Properties}

Static direct-current (DC) magnetization measurements were performed ranging from 1.8 to $300 \mathrm{~K}$ under an external magnetic field of $1 \mathrm{kOe}$ on the polycrystalline samples of 1 . At $300 \mathrm{~K}$, the complex 1 shows its $\chi_{\mathrm{M}} T$ value of about $3.21 \mathrm{~cm}^{3} \mathrm{~K} \mathrm{~mol}^{-1}$ in Figure $2 \mathrm{a}$. This $\chi_{\mathrm{M}} T$ value is much larger than that of isolated high spin $\mathrm{Co}(\mathrm{II})(\mathrm{S}=3 / 2$ and $\mathrm{g}=2.0)$ of 1.87 $\mathrm{cm}^{3} \mathrm{~mol}^{-1} \mathrm{~K}$. The large $\chi_{\mathrm{M}} T$ in complex usually originates from spin-orbit coupling [8]. The $\chi_{\mathrm{M}} T$ values first decrease gradually as the room temperature decreases to $150 \mathrm{~K}$, then shows a sharp decrease as the temperature lowers, finally reaching the ultimate values of $2.16 \mathrm{~cm}^{3} \mathrm{~mol}^{-1} \mathrm{~K}$ at $1.8 \mathrm{~K}$. This is commonly owned to the depopulation of Kramers excited state levels $\left(M_{\mathrm{J}}= \pm 3 / 2\right.$ and $\left.\pm 5 / 2\right)$. Therefore, $\mathrm{M}(\mathrm{H})$ characteristics of complex 1 at 1.8, 2.5, 5.0 and $10 \mathrm{~K}$ were measured under a field ranging from 0 to $7 \mathrm{~T}$ in the inset of Figure $2 \mathrm{~b}$. At $1.8 \mathrm{~K}$, complex 1 increases continuously to $2.46 \mathrm{~N} \mu_{\mathrm{B}}$ at $7 \mathrm{~T}$. This nonsaturation with a high-field further shows an obviously magnetic anisotropy of complex 1. To further confirm the magnetic anisotropy of complex 1 , the corresponding reduced magnetization was shown in Figure $2 \mathrm{~b}$. The magnetization of $2.46 \mathrm{~N} \mu_{\mathrm{B}}$ at $7 \mathrm{~T}$ is as expected for an anisotropic ion. By utilizing the PHI program, the anisotropy parameters of complex 1 can be quantified from the temperature and field-dependent magnetization data [46]. Good fits could be obtained by using the following spin Hamiltonian:

$$
\hat{H}=D\left[\hat{S}_{z}^{2}-\frac{S(S+1)}{3}\right]+E\left(\hat{S}_{x}^{2}-\hat{S}_{y}^{2}\right)+g \mu_{\mathrm{B}} S H
$$

where $D$ is the axial parameter and $E$ is parameter of rhombic zero-field-splitting parameter respectively, $S$ is the spin projection and the last term is the Zeeman. The best fits of the reduced magnetization data show $D=67.63(22) \mathrm{cm}^{-1}, E=-16.29(15) \mathrm{cm}^{-1}, g=2.77(3)$ and TIP $=1.21 \times 10^{-4}$ for complex 1 . This positive $D$ value can be mainly owned to the coupled states between ground and excited states. 


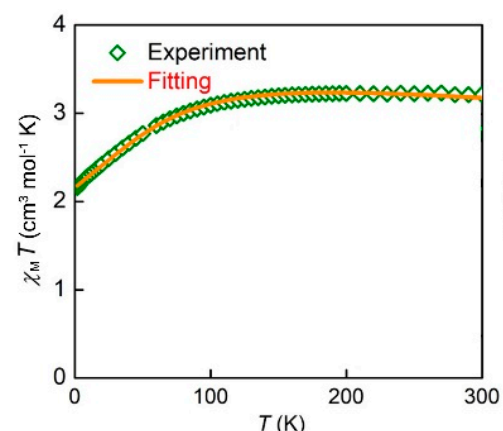

(a)

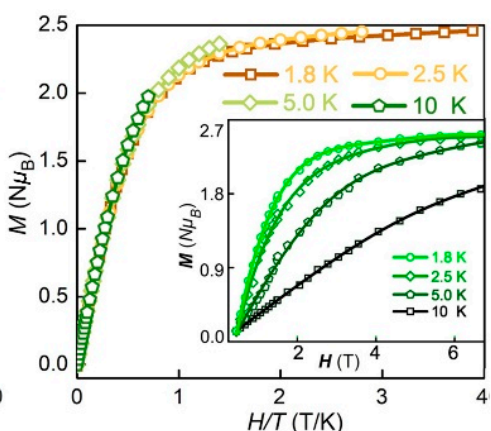

(b)

Figure 2. (a) Temperature-dependent $\chi_{\mathrm{M}} T$ for 1 . The solid line is fitted by PHI; (b) Isothermal reduced magnetization at different temperatures for 1. Insert: Experimental $\mathrm{M}(\mathrm{H})$ plots at different temperatures for $\mathbf{1}$. Solid lines represent the best fit.

To probe the magnetic relaxation dynamics, the magnetic susceptibilities were measured. For complex 1, there is no obvious signal of $\chi_{\mathrm{M}}$ " of AC susceptibility (out-of-plane) at $2 \mathrm{~K}$. However, typical signals of $\chi_{\mathrm{M}}{ }^{\prime \prime}$ can be observed directly, when an external DC magnetic field is applied. Figure 3 shows the typically frequency-dependent AC magnetic susceptibility under different magnetic fields from 0 to $2.5 \mathrm{kOe}$ at $2.0 \mathrm{~K}$. Such behavior is associated with the appearance of quantum tunneling of the magnetization (QTM) [12]. This result indicates that each molecule of complex 1 containing a cobalt behaves as a field-induced SIM. To further explore the magnetostructural correlation, $1.5 \mathrm{kOe}$ was the best to be chosen to measure the dynamic magnetization due to the longest relaxation time. The variable frequency $\chi_{\mathrm{M}}{ }^{\prime}$ and $\chi_{\mathrm{M}}{ }^{\prime \prime}$ for 1 at temperatures ranging from 1.8 to $4.5 \mathrm{~K}$ are shown in Figure $4 a, b$, respectively. Obvious frequency-dependent out-of-phase peaks could be observed at the temperature from 1.8 to $4.5 \mathrm{~K}$ in Figure $4 \mathrm{~b}$. Such behavior is commonly related to the super-paramagnet-like slow magnetic relaxation in a typical SIM. Then, plots of $\chi_{\mathrm{M}}{ }^{\prime \prime}$ vs. $\chi_{\mathrm{M}}{ }^{\prime}$ (Cole-Cole plot) for complex 1 were fitted well by using the CCFIT2 program and the modified Debye function (Figure 5a) [47]. From the Arrhenius-like diagrams in Figure $5 \mathrm{~b}$ and Table S4, relaxation times $\left(\tau_{0}\right)$ and effective barrier energies could be calculated. Equation (1) was applied to fit, which contains three relaxation processes, where $A$ means the direct process, $B$ indicates the process of Raman, $U_{\text {eff }}$ means the effective energy barrier of magnetization reversal. According to these corresponding data, these fitted parameters are $A=43.54 \mathrm{~K}^{-1} \mathrm{~S}^{-1}, B=1.22 \times \mathrm{K}^{-4.67} \mathrm{~S}^{-1}, n=4.67$ respectively. We can also gain that $\tau_{0}$ is $2.11 \times 10^{-8} \mathrm{~s}$ of the slow relaxation time. $U_{\text {eff }}$ shows a large value of about $43.28 \mathrm{~K}$. $U_{\text {eff }}$ is much larger than the ones in most mononuclear Co complexes ever reported.

$$
\tau^{-1}=A T+B T^{n}+\tau_{\mathrm{o}}{ }^{-1} \exp \left(-U_{\mathrm{eff}} / k_{\mathrm{B}} T\right) .
$$

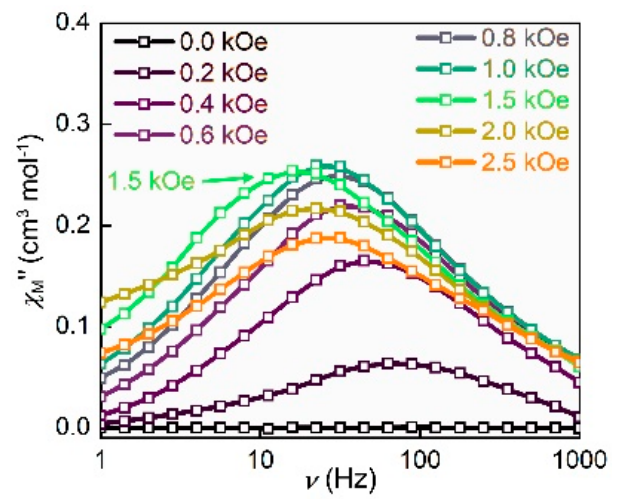

Figure 3. Isothermal field-dependent magnetic characteristics performed on polycrystalline sample of complex 1 at $2 \mathrm{~K}$. 


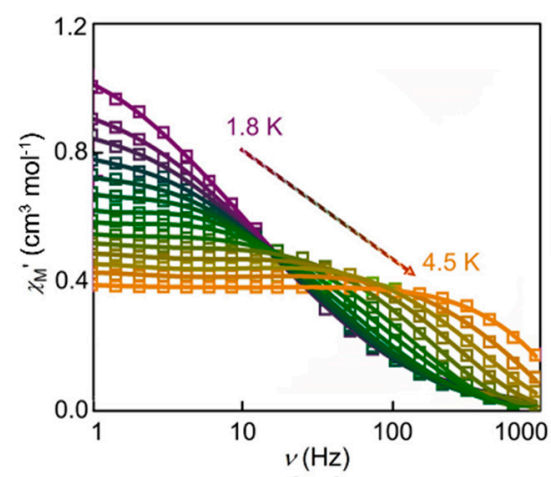

(a)

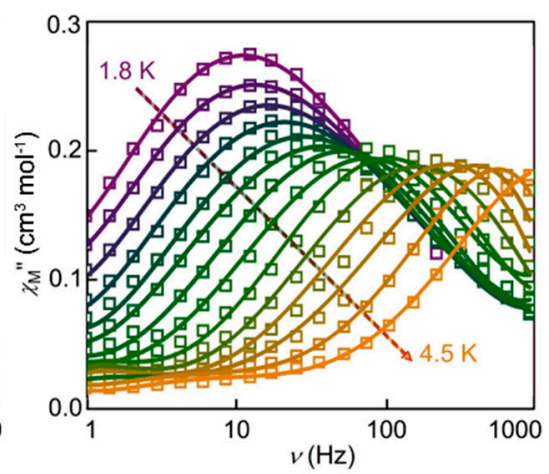

(b)

Figure 4. Frequency-dependent $\chi_{\mathrm{M}^{\prime}}$ (a) and $\chi_{M}{ }^{\prime \prime}$ (b) AC susceptibilities in $H_{\mathrm{DC}}=1.5 \mathrm{kOe}$ for complex 1 .

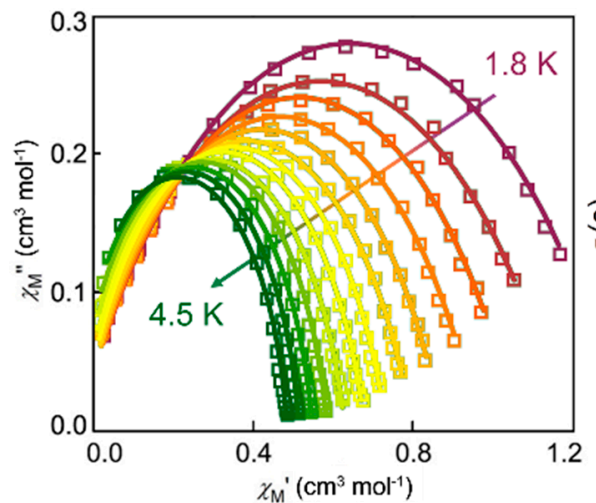

(a)

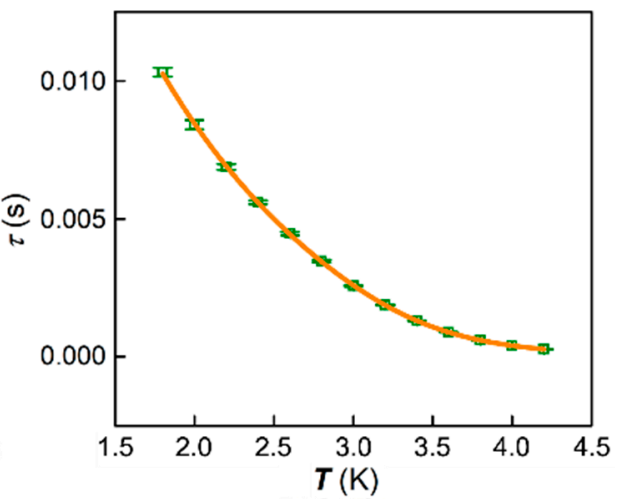

(b)

Figure 5. (a) The Cole-Cole curves of complex 1. Solid lines are fitted by CCFIT2; (b) Plot of $\tau_{0}$ versus $T$ for complex 1, where the orange solid line represents the fitted results using CCFIT2.

Compared with other mononuclear Co(II) complexes [22,27-37], the $\chi_{\mathrm{M}} T$ value of $3.21 \mathrm{~cm}^{3} \mathrm{~K} \mathrm{~mol}^{-1}$ in $\mathbf{1}$ is much larger than other Co based complexes. This result may be due to the long axial Co-O bond formed by Co1 and O3 (Co1 . . O3 distance is $2.4265 \AA$ ), which certainly is not a coordination bond. Owing to the long axial $\mathrm{Co}-\mathrm{O}$ bond, the $\mathrm{Co}(\mathrm{II})$ complex shows the distorted elongated octahedron. Therefore, the larger $\chi_{\mathrm{M}} T$ values look like the one in six coordination Co(II) complexes. On the other hand, the distorted elongated octahedron could further change the electron density between $\mathrm{Co}(\mathrm{II})$ and $\mathrm{O}$ ions. We applied the first-principles calculations based on the density functional theory (DFT) to evaluate the distribution of spin state with different length of axial $\mathrm{Co}-\mathrm{O}$ bond in Figure S1. There is a strong relationship between the distribution of spin state and the length of axial Co-O bond. The complex with longer axial $\mathrm{Co}-\mathrm{O}$ bond, shows the existence of spin states. Furthermore, the charge density difference was calculated to distinctly analyze the charge variation with different spin states. Figure S2 and Figure S3 shows that Co1 donates more charge and $\mathrm{O} 3$ accepts more charge with a spin up state (longer axial $\mathrm{Co}-\mathrm{O}$ bond) than those without a spin state (shorter axial Co-O bond). Meanwhile, the charge transfer is relatively less between spin up and spin down states. Therefore, we conclude that the long axial Co-O bond in complex 1 may play an important role in increasing the effective energy barriers up to $43.28 \mathrm{~K}$. However, the effective energy barriers of most mononuclear Co(II) complexes are lower than $20 \mathrm{~K}$.

\section{Discussion}

We report a mononuclear Co(II) complex with the distorted elongated octahedral geometry. The result value of $D$ obtained by fitting the DC susceptibility is positive, 
indicating that complex $\mathbf{1}$ is an easy-plane complex. Furthermore, complex $\mathbf{1}$ is a typical SIM representing field induced slow-relaxation. AC magnetic susceptibility measurement results confirm that complex 1 is a field-induced SIM with a high effective energy barrier $U_{\text {eff }}$ of above $43.28 \mathrm{~K}$ and relaxation time $\tau_{0}=2.11 \times 10^{-8} \mathrm{~s}$. By DFT calculation, this high effective energy barrier and high $\chi_{\mathrm{M}} T$ value of complex 1 could be originated from the distorted elongated octahedron environment caused by the long axial Co-O bond. These results may offer a different strategy to improve blocking the temperature of a single-ion magnet.

Supplementary Materials: The following supporting information can be downloaded at: https: / / www.mdpi.com/article/10.3390/nano12040707/s1, Table S1: Crystallographic data and structural refinement parameters for complex1; Table S2: Bond lengths [A] and angles [deg] for 1; Table S3: Deviation parameters calculated by SHAPE from each ideal polyhedron for complex Co1; Table S4: The fit parameters of the analyses of the ac susceptibilities of 1 under $1.5 \mathrm{kOe}$ bias DC field; Figure S1: Structures for complex 1 with different length of axial Co-O bonds. Figure S2: Charge density difference between different spin states. Figure S3: The standard distribution of electron density determined by single-crystal X-ray diffraction; Structure S1: crystallographic CIF. References [48-51] are cited in the Supplementary Materials.

Author Contributions: Conceptualization, Z.X. and Y.L.; methodology, C.J.; writing draft, J.Z.; editing, Y.J. and C.M.; project administration J.G. All authors have read and agreed to the published version of the manuscript.

Funding: This work is supported by the National Natural Science Foundation of China (No. 62004136), and Natural Science Foundation of the Jiangsu Higher Education Institutions of China (20KJB140019 and 19KJB150018). This work is supported by Innovation and Entrepreneurship Training Program for College Students (202110332020Z). This work is supported by Doctor of Entrepreneurship and Innovation in Jiangsu Province (No. (2020)30790).

Institutional Review Board Statement: Not applicable.

Informed Consent Statement: Not applicable.

Data Availability Statement: Not applicable.

Conflicts of Interest: The authors declare no conflict of interest.

\section{References}

1. Ishikawa, N.; Sugita, M.; Ishikawa, T.; Koshihara, S.Y.; Kaizu, Y. Lanthanide double-decker complexes functioning as magnets at the single-molecular level. J. Am. Chem. Soc. 2003, 125, 8694-8695. [CrossRef] [PubMed]

2. Wang, Y.; Li, X.L.; Wang, T.W.; Song, Y.; You, X.Z. Slow relaxation processes and single-ion magnetic behaviors in dysprosiumcontaining complexes. Inorg. Chem. 2010, 49, 969-976. [CrossRef] [PubMed]

3. Wang, H.S.; Chen, Y.; Hu, Z.B.; Long, Q.Q.; Yin, C.L.; Zhang, Z.C.; Pan, Z.Q. A Dy-based complex with the magnetic relaxation behavior regulated by enclosing one Dy ${ }^{\mathrm{III}}$ ion into a Calixarene ligand. Inorg. Chem. Commun. 2019, 105, 76-81. [CrossRef]

4. Yu, S.; Chen, Z.; Hu, H.; Li, B.; Liang, Y.; Liu, D.; Zou, H.; Yao, D.; Liang, F. Two mononuclear Dysprosium(III) complexes with their slow magnetic relaxation behaviors tuned by coordination geometry. Dalton Trans. 2019, 48, 16679-16686. [CrossRef]

5. Chen, Z.; Yu, S.; Wang, R.; Li, B.; Yin, B.; Liu, D.; Liang, Y.; Yao, D.; Liang, F. Three Dy(III) single-ion magnets bearing the tropolone ligand: Structure, magnetic properties and theoretical elucidation. Dalton Trans. 2019, 48, 6627-6637. [CrossRef]

6. Liu, J.; Chen, Y.C.; Liu, J.L.; Vieru, V.; Ungur, L.; Jia, J.H.; Chibotaru, L.; Lan, F.Y.; Wernsdorfer, W.; Gao, S.; et al. A stable pentagonal bipyramidal Dy(III) single-ion magnet with a record magnetization reversal barrier over $1000 \mathrm{~K}$. J. Am. Chem. Soc. 2016, 138, 5441-5450. [CrossRef]

7. Li, J.; Yuan, C.; Yang, L.; Kong, M.; Zhang, J.; Ge, J.Y.; Zhang, Y.Q.; Song, Y. Magnetic anisotropy along a series of lanthanide polyoxometalates with pentagonal bipyramidal symmetry. Inorg. Chem. 2017, 56, 7835-7841. [CrossRef]

8. Guo, F.S.; Day, B.M.; Chen, Y.C.; Tong, M.L.; Mansikkamäki, A.; Layfield, R.A. Magnetic hysteresis up to 80 kelvin in a dysprosium metallocene single-molecule magnet. Science 2018, 362, 1400-1403. [CrossRef]

9. Murrie, M. Cobalt(II) single-molecule magnets. Chem. Soc. Rev. 2010, 39, 1986-1995. [CrossRef]

10. Craig, G.A.; Murrie, M. 3d single-ion magnets. Chem. Soc. Rev. 2015, 44, 2135-2147. [CrossRef]

11. Yao, X.N.; Du, J.Z.; Zhang, Y.Q.; Leng, X.B.; Yang, M.W.; Jiang, S.D.; Wang, Z.X.; Ouyang, Z.W.; Deng, L.; Wang, B.W.; et al. Two-coordinate Co(II) imido complexes as outstanding single molecule magnets. J. Am. Chem. Soc. 2017, 139, 373-380. [CrossRef] [PubMed] 
12. Deng, Y.F.; Han, T.; Yin, B.; Zheng, Y.Z. On balancing the QTM and the direct relaxation processes in single-ion magnets-The importance of symmetry control. Inorg. Chem. Front. 2017, 4, 1141-1148. [CrossRef]

13. Yao, X.; Yan, P.F.; An, G.H.; Li, Y.X.; Li, W.Z.; Li, G.M. Investigation of magneto-structural correlation based on a series of seven-coordinated -diketone Dy(III) single-ion magnets with $C_{2 \mathrm{v}}$ and $C_{3 \mathrm{v}}$ local symmetry. Dalton Trans. 2018, 47, 3976-3984. [CrossRef] [PubMed]

14. Cao, D.K.; Feng, J.Q.; Ren, M.; Gu, Y.W.; Song, Y.; Ward, M.D. A mononuclear cobalt(II)-dithienylethene complex showing slow magnetic relaxation and photochromic behavior. Chem. Commun. 2013, 49, 8863-8865. [CrossRef]

15. Hu, Z.B.; Feng, X.; Li, J.; Zhang, Y.Q.; Yin, L.; Wang, Z.; Ouyang, Z.; Kurmoo, M.; Song, Y. Optimal diamagnetic dilution concentration for suppressing the dipole-dipole interaction in single-ion magnets. Dalton Trans. 2020, 49, 2159-2167. [CrossRef]

16. Vallejo, J.; Castro, I.; Ruiz-García, R.; Cano, J.; Julve, M.; Lloret, F.; De Munno, G.; Wernsdorfer, W.; Pardo, E. Field-induced slow magnetic relaxation in a six-coordinate mononuclear cobalt(II) complex with a positive anisotropy. J. Am. Chem. Soc. 2012, 134, 15704-15707. [CrossRef]

17. Colacio, E.; Ruiz, J.; Ruiz, E.; Cremades, E.; Krzystek, J.; Carretta, S.; Cano, J.; Guidi, T.; Wernsdorfer, W.; Brechinm, E.K. Slow magnetic relaxation in a Co ${ }^{\mathrm{II}} \mathrm{Y}^{\mathrm{III}}$ single-ion magnet with positive axial zero-field splitting. Angew. Chem. Int. Ed. 2013, 52, 9130-9134. [CrossRef]

18. Hu, Z.B.; Jing, Z.Y.; Li, M.M.; Yin, L.; Gao, Y.D.; Yu, F.; Hu, T.P.; Wang, Z.; Song, Y. Important Role of Intermolecular Interaction in Cobalt(II) Single-Ion Magnet from Single Slow Relaxation to Double Slow Relaxation. Inorg. Chem. 2018, 57, 10761-10767. [CrossRef]

19. Huang, X.C.; Zhou, C.D.; Shao, J.; Wang, X.Y. Field-induced slow magnetic relaxation in Cobalt(II) compounds with pentagonal bipyramid geometry. Inorg. Chem. 2014, 53, 12671-12673. [CrossRef]

20. Chen, L.; Wang, J.; Wei, J.M.; Wernsdorfer, W.; Chen, X.T.; Zhang, Y.Q.; Song, Y.; Xue, Z.L. Slow magnetic relaxation in a mononuclear eight-coordinate Cobalt(II)complex. J. Am. Chem. Soc. 2014, 136, 12213-12216. [CrossRef]

21. Zhang, J.; Li, J.; Yang, L.; Yuan, C.; Zhang, Y.Q.; Song, Y. Magnetic anisotropy from trigonal prismatic to trigonal antiprismatic Co(II) complexes:experimental observation and theoretical prediction. Inorg. Chem. 2018, 57, 3903-3912. [CrossRef] [PubMed]

22. Bunting, P.C.; Atanasov, M.E.; Damgaard-Møller, M.; Perfetti, I.; Crassee, M.; Orlita, J.; Overgaard, M.; Slageren-Van, J.; Neese, F.; Long, J.R. A linear cobalt(II) complex with maximal orbital angular momentum from a non-Aufbau ground state. Science 2018, 362, 7319. [CrossRef] [PubMed]

23. Woods, T.J.; Ballesteros-Rivas, M.F.; Gómez-Coca, S.; Ruiz, E.; Dunbar, K.R. Relaxation dynamics of identical trigonal bipyramidal Cobalt molecules with different local symmetries and packing arrangements: Magnetostructural correlations and ab inito calculations. J. Am. Chem. Soc. 2016, 138, 16407-16416. [CrossRef]

24. Collet, A.; Craig, G.A.; Heras-Ojea, M.J.; Bhaskaran, L.; Wilson, C.; Hill, S.; Murrie, M. Slow magnetic relaxation in a $\left\{\left(\mathrm{Co}^{\mathrm{II}} \mathrm{Co}^{\mathrm{III}} 2\right)\right\}$ complex containing a high magnetic anisotropy trigonal bipyramidal Co ${ }^{\mathrm{II}}$ centre. Dalton Trans. 2018, 47, 9237-9240. [CrossRef] [PubMed]

25. Hou, X.; Wang, X.; Liu, X.; Wang, J.; Tang, L.; Ju, P. Fine-tuning the effects of auxiliary ligands on two trigonal-bipyramid cobalt(II) complexes exhibiting field-induced slow magnetic relaxation. New J. Chem. 2018, 42, 8583-8590. [CrossRef]

26. Cui, H.H.; Wang, J.; Chen, X.T.; Xue, Z.L. Slow magnetic relaxation in five-coordinate spin-crossover cobalt(II) complexes. Chem. Commun. 2017, 53, 9304-9307. [CrossRef]

27. Shaffer, D.; Bhowmick, W.I.; Rheingold, A.L.; Tsay, C.; Livesay, B.N.; Shores, M.P.; Yang, J.Y. Spin-state diversity in a series of Co(II) PNP pincer bromide complexes. Dalton Trans. 2016, 45, 17910-17917. [CrossRef]

28. Brachňaková, B.; Matejová, S.; Moncol, J.; Herchel, R.; Pavlik, J.; Moreno-Pineda, E.; Ruben, M.; Šalitroš, I. Stereochemistry of coordination polyhedra vs. single ion magnetism in penta- and hexacoordinated $\mathrm{Co}(\mathrm{II})$ complexes with tridentate rigid ligands. Dalton Trans. 2020, 49, 1249-1264. [CrossRef]

29. Shao, F.; Cahier, B.; Guihéry, N.; Rivière, E.; Guillot, R.; Barra, A.L.; Lan, Y.; Wernsdorfer, W.; Campbell, V.E.; Mallah, T. Tuning the Ising-type anisotropy in trigonal bipyramidal Co(II) complexes. Chem. Commun. 2015, 51, 16475-16478. [CrossRef]

30. Ruamps, R.L.; Batchelor, J.; Guillot, R.; Zakhia, G.; Barra, A.L.; Wernsdorfer, W.; Guihéry, N.; Mallah, T. Ising-type magnetic anisotropy and single molecule magnet behaviour in mononuclear trigonal bipyramidal Co(II) complexes. Chem. Sci. 2014, 5, 3418-3424. [CrossRef]

31. Nemec, I.; Herchel, R.; Trávníček, Z. Ferromagnetic coupling mediated by Co center dot center dot center dot pi non-covalent contacts in a pentacoordinate $\mathrm{Co}(\mathrm{II})$ compound showing field-induced slow relaxation of magnetization. Dalton Trans. 2016, 45, 12479-12482. [CrossRef] [PubMed]

32. Rajnák, C.; Titiš, J.; Fuhr, O.; Ruben, M.; Boča, R. Single-molecule magnetism in a pentacoordinate Cobalt(II) complex supported by an antenna ligand. Inorg. Chem. 2014, 53, 8200-8202. [CrossRef] [PubMed]

33. Mondal, A.K.; Goswami, T.; Misra, A.; Konar, S. Probing the effects of ligand field and coordination geometry on magnetic anisotropy of pentacoordinate Cobalt(II) single-ion magnets. Inorg. Chem. 2017, 56, 6870-6878. [CrossRef] [PubMed]

34. Świtlicka, A.; Machura, B.; Penkala, M.; Bieńko, A.; Bieńko, D.C.; Titiš, J.; Rajnák, C.; Boča, R.; Ozarowski, A.; Ozerov, M. Slow magnetic relaxation in Cobalt(II) field-induced single-ion magnets with positive large anisotropy. Inorg. Chem. 2018, 57, 12740-12755. [CrossRef] 
35. Schweinfurt, D.; Sommer, M.G.; Atanasov, M.; Demeshko, S.; Hohloch, S.; Meyer, F.; Neese, F.; Sarkar, B. The ligand field of the azido ligand: Insights into bonding parameters and magnetic anisotropy in a Co(II)-azido complex. J. Am. Chem. Soc. 2015, 137, 1993-2005. [CrossRef]

36. Mondal, A.; Mondal, A.; Konar, S. Field induced single ion magnetic behaviour in square-pyramidal Cobalt(II) complexes with easy-plane magnetic anisotropy. Magnetochemistry 2019, 5, 12. [CrossRef]

37. Mondal, A.K.; Jover, J.; Ruiz, E.; Konar, S. Investigation of easy-plane magnetic anisotropy in P-ligand square-pyramidal Co ${ }^{\mathrm{II}}$ single ion magnets. Chem. Commun. 2017, 53, 5338-5341. [CrossRef]

38. Nemec, I.; Liu, H.; Herchel, R.; Zhang, X.; Trávníček, Z. Magnetic anisotropy in pentacoordinate 2,6-bis(arylazanylidene-1chloromethyl)pyridine cobalt(II) complexes with chlorido co-ligands. Synth. Met. 2016, 215, 158-163. [CrossRef]

39. Zeng, H.P.; Qi, W.; Zhai, L.X.; Wang, F.S.; Zhang, J.; Li, D. Preparation and characterization of sludge-based magnetic biochar by pyrolysis for methylene blue removal. Nanomaterials 2021, 11, 2473. [CrossRef]

40. Wang, H.; Zhang, X.; Wang, Y.; Quan, G.X.; Han, X.Y.; Yan, J.L. Facile synthesis of magnetic nitrogen-doped porous carbon from bimetallic metal-organic frameworks for efficient norfloxacin removal. Nanomaterials 2018, 8, 664. [CrossRef]

41. Matias, I.A.; Ribeiro, A.C.; Ferraria, A.M.; Rego, A.M.; Martins, L.M. Catalytic performance of a magnetic core-shell Iron(II) c-scorpionate under unconventional oxidation conditions. Nanomaterials 2020, 10, 2111. [CrossRef] [PubMed]

42. Liu, Y.; Dou, J.; Wang, D.; Li, D.; Gao, Z.; Chem, J. Synthesis and crystal structures of two new complexescenter dot $\left[\mathrm{M}(\mathrm{OH})_{2}(\mathrm{HDPA})_{2}\right] \cdot 3 \mathrm{H}_{2} \mathrm{O}(\mathrm{M}=\mathrm{Mn}, \mathrm{Co})$. J. Chem. Crystallogr. 2006, 36, 613-618. [CrossRef]

43. Sheldrick, G.M. A short history. Acta. Crystallogr. A 2008, 64, 112-122. [CrossRef] [PubMed]

44. Zhang, J.; Wu, S.; Zhu, X.; Shen, J.; Ji, K.; Zhang, R. Low-magnetic-feld controlled magnetodielectric coupling at room temperature in a chiral layered diphenylalanine-based 1D-coordination-polymer. J. Phys. D Appl. Phys. 2020, 53, 15LT01. [CrossRef]

45. Jiang, Y.C.; He, A.P.; Zhao, R.; Chen, Y.; Liu, G.Z.; Lu, H.; Zhang, J.L.; Zhang, Q.; Wang, Z.; Zhao, C.; et al. Coexistence of photoelectric conversion and storage in van der Waals heterojunctions. Phys. Rev. Lett. 2021, 127, 217401. [CrossRef]

46. Chilton, N.F.; Anderson, R.P.; Turner, L.D.; Soncini, A.; Murray, K.S. PHI: A powerful new program for the analysis of anisotropic monomeric and exchange-coupled polynuclear d- and f-block complexes. J. Comput. Chem. 2013, 34, 1164-1175. [CrossRef]

47. Guo, Y.N.; Xu, G.F.; Guo, Y.; Tang, J. Relaxation dynamics of dysprosium(III) single molecule magnets. Dalton Trans. 2011, 40, 9953-9963. [CrossRef]

48. Perdew, J.P.; Burke, K.; Ernzerhof, M. Generalized gradient approximation made simple. Phys. Rev. Lett. 1996, 77, 3865-3868. [CrossRef]

49. Hohenberg, P.; Kohn, W. Inhomogeneous electron gas. Phys. Rev. B 1964, 136, B864-B865. [CrossRef]

50. Kresse, G.; Furthmuller, J. Efficiency of ab-initio total energy calculations for metals and semiconductors using a plane-wave basis set. Comput. Mater. Sci. 1996, 6, 15-50. [CrossRef]

51. Zhou, F.; Cococcioni, M.; Marianetti, C.A.; Morgan, D.; Ceder, G. First-principles prediction of redox potentials in transition-metal compounds with LDA + U. Phys. Rev. B: Condens. Matter Mater. Phys. 2004, 70, 235121. [CrossRef] 